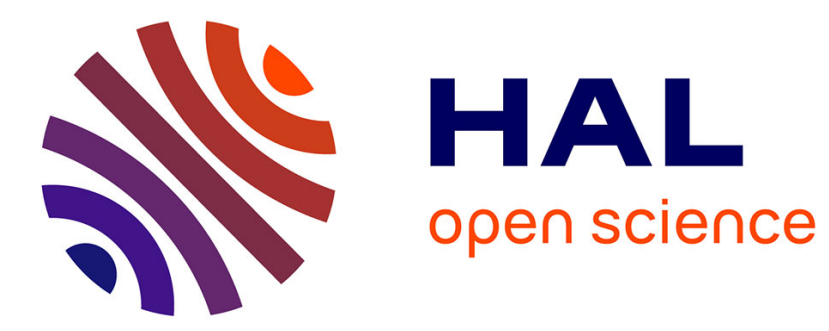

\title{
The evaluation and costs of transition programs for youth with epilepsy
}

Rima Nabbout, Alexis Arzimanoglou, Richard F.M. Chin, Zachary Grinspan, Kathy Speechley, Peter Camfield

\section{- To cite this version:}

Rima Nabbout, Alexis Arzimanoglou, Richard F.M. Chin, Zachary Grinspan, Kathy Speechley, et al.. The evaluation and costs of transition programs for youth with epilepsy. Epilepsy \& Behavior, 2019, 93, pp.133 - 137. 10.1016/j.yebeh.2018.12.014 . hal-03486420

\section{HAL Id: hal-03486420 \\ https://hal.science/hal-03486420}

Submitted on 20 Dec 2021

HAL is a multi-disciplinary open access archive for the deposit and dissemination of scientific research documents, whether they are published or not. The documents may come from teaching and research institutions in France or abroad, or from public or private research centers.
L'archive ouverte pluridisciplinaire $\mathbf{H A L}$, est destinée au dépôt et à la diffusion de documents scientifiques de niveau recherche, publiés ou non, émanant des établissements d'enseignement et de recherche français ou étrangers, des laboratoires publics ou privés.

\section{(ㄷ)(1) $\$$}

Distributed under a Creative Commons Attribution - NonCommerciall 4.0 International 
Title: The evaluation and costs of transition programs for youth with epilepsy

Rima Nabbout ${ }^{1}$, Alexis Arzimanoglou ${ }^{2}$, Richard FM Chin ${ }^{3}$, Zachary Grinspan ${ }^{4}$, Kathy Speechley ${ }^{5}$, Peter Camfield ${ }^{6}$.

Affiliations

${ }^{1}$ Reference centre for rare epilepsies, Department of Pediatric Neurology, Necker Enfants Malades Hospital, Imagine Institute, INSERM 1163, Paris Descartes University, Paris, France.

${ }^{2}$ Epilepsy Department, University Hospitals of Lyon, Lyon, France

${ }^{3}$ Muir Maxwell Epilepsy Centre, Department of Child Life and Health, University of Edinburgh, Edinburgh, UK.

${ }^{4}$ Departments of Healthcare Policy \& Research and Pediatrics Weill Cornell Medicine, New York, NY

${ }^{5}$ Departments of Paediatrics and Epidemiology \& Biostatistics, Western University; Children's Health Research Institute, Lawson Health Research Institute, London, ON, Canada

${ }^{6}$ Department of Pediatrics, Dalhousie University, Halifax, Nova Scotia, Canada

Corresponding author: Dr. Rima Nabbout, Hôpital Necker Enfants Malades, Université Paris Descartes, Institut Imagine, 149 rue de Sèvres, 75015 Paris, France; email rimanabbout@yahoo.com, rima.nabbout@aphp.fr

Word count abstract 327

Word count body of paper: 3084

Page numbers: 15

Key words: epilepsy; childhood; transition; evaluation; cost effectiveness; outcome 


\section{Abstract}

There is limited information about the effectiveness of transition programs for youth moving from pediatric to adult care with any chronic disease. Two Delphi studies and NICE guidelines about transition for epilepsy have suggested few critical outcome measures for transition. A single large prospective study found that the most important transition program elements were appropriate parent involvement, promotion of health self-efficacy, and meeting the adult team before transfer. Two Cochrane reviews of the value of transition for epilepsy found insufficient evidence to establish or refute the value of various programs, although evaluation of a few programs suggested a great deal of family/patient satisfaction. The cost of transition programs and their cost effectiveness have also not been established except for renal transplantation where transition programs were associated with fewer losses of the transplanted kidneys, a costeffective outcome. Published data on the overall cost of care for children and adults with epilepsy may be helpful to establish a business plan for a transition program, and are briefly reviewed. Establishing cost effectiveness of transition programs for epilepsy would promote their establishment and viability. However, a number of studies will be needed based on the nature of the program, the health care system where it is carried out, and the type of epilepsy. In fee-for-service health systems the re-evaluation of epilepsy patients prior to transfer may be sufficient to cover the costs of the transition program, whereas in single payer systems, there may be positive downstream health or societal benefits that justify the costs. A theoretical framework for comprehensive evaluation of epilepsy transition programs is needed. The Triple Aim Framework seems applicable with focus on population health, patient experiences and cost and has the potential to assess transition interventions in the context of system-wide improvements in health care. Transition programs in general have not been well evaluated and very little evaluation data exist regarding transition programs for epilepsy. We recommend more evaluative research using rigorous methodology to comprehensively assess these programs. 


\section{Introduction}

There is increasing evidence of the potential value of transition programs for adolescents with epilepsy to allow a smooth transfer to adult care and an improved adult life; however for the most part, this "evidence" is descriptive and not based on rigorous methodology. A closed seminar about transition to adult care for youth with epilepsy took place near Paris, France in July 2018. This symposium followed two previous ones, the first aiming to take transition out of the shadows in the context of different epilepsy syndromes ${ }^{1}$ and the second to outline biologic, social, treatment and outcome issues ${ }^{2-4}$. An accompanying paper from the current symposium outlines how transition for epilepsy might be best orchestrated based on the programs and experience in many countries. ${ }^{5}$ The current paper summarizes the discussion about the evaluation of epilepsy transition programs and their cost.

\section{Evaluation of epilepsy transition programs}

To evaluate the utility of epilepsy transition programs, the goals of the programs need to be clear. As seen in Table 1, there are relatively few common elements across a variety of recommendations for transition programs.

A Delphi study was carried out by an international group of experts to try to identify critical features for most transition programs regardless the disease. Thirty-seven panelists included 24 physicians, 8 nurses, 2 psychologists, 2 transition program managers, and 1 research director. The process started with 34 key elements and 32 indicators. ${ }^{6}$ After three rounds of the Delphi process only 4 key elements were nominated as essential by $\geq 70 \%$ of the experts. These were: 1 ) starting transition planning at an early age, 2) discussing with the patient and family about selfmanagement, including the young person's views and preferences for transition planning, 3) seeing the adolescent alone at least for part of the transition (if developmentally appropriate), and 4) identifying an adult professional willing to take on the young person.

Ten additional factors were rated as "essential or very important" by $\geq 70 \%$ of the "experts" with eight of the ten rated as essential or very important by $>85 \%$ of experts. These were: tailoring the transition plan to the needs of the patient and family; identifying someone within the team to play the role of transition manager or coordinator; providing a written health and bio-psychosocial profile summary to the patient and adult care provider before transfer; having a written transition protocol/plan that is available to patients, parents and providers; making sure that at least one appointment with adult provider after transfer is scheduled and confirmed; verifying that the pediatric and adult clinics in question have sufficient knowledge and skills in adolescent health, including parents/legal representatives in the process of transition; informing primary care providers (pediatrician, GP, family doctor, nurse practitioner/advanced practice nurse) of the transition process; putting in place mechanisms/resources to contact patients lost to follow-up; discussing with patient and 
family the differences between pediatric and adult care; and finally, discussing with the patient risk behaviors and their influence on health. It is perhaps surprising that all of these suggestions are related to health outcomes and none to psychosocial development given the more global goal of a successful adult life. A potential explanation may be that there were no patient or parental representatives on the expert panel.

Many of the final ten elements listed above are similar to a comprehensive set of nine transition program principles outlined by the United Kingdom's National Institute for Health and Care Excellence (NICE) guidelines of 2016 on transition including: agebanded clinic, meeting with the adult team before transfer, promotion of health selfefficacy, written transition plan, appropriate parental involvement, key transition worker for each person, coordinated health care team, holistic life skills training and a transition manager for the clinical team. ${ }^{7}$ A careful study of these NICE program features followed 374 youth with diabetes, autism and cerebral palsy annually for four years after transfer to adult care. ${ }^{8}$ Based on four outcomes measures: Warwick Edinburgh Mental Wellbeing Scale, Mind the Gap Scale (a scale to measure satisfaction with services), Rotterdam Transition Profile (Participation) and Autonomy in Appointments), the authors found that of the nine elements, only three were associated with good outcome appropriate parent involvement, promotion of health self-efficacy and meeting the adult team before transfer. This is an important study because it not only points to the elements of a good transition program, but it also gives some focus to what should be assessed in establishing the potential value of a transition program for children with epilepsy.

A Cochrane meta-analysis in 2016 entitled: "Transition of care for adolescents from paediatric services to adult health services" only identified four randomized controlled trials that assessed transition programs. ${ }^{9}$ These were small studies including a total of 238 patients and the authors concluded that "There was evidence of improvement in patients' knowledge of their condition in one study, and improvements in self-efficacy and confidence in another, but since few studies were eligible for this review, and the overall certainty of the body of this evidence is low, no firm conclusions can be drawn about the effectiveness of the evaluated interventions. Further research is very likely to have an important impact on our confidence in the intervention effect and likely could change our conclusions. There is considerable scope for the rigorous evaluation of other models of transitional care, reporting on clinical outcomes with longer term followup."

Another systematic study examined outcome measurements in publications about transition. ${ }^{10}$ The authors found only 26 publications that examined outcome after transfer and noted that the interventions were complex with multiple outcomes, major problems with blinding, and small sample sizes. Only a few studies were randomized and there were problems of "recruitment and external validity, blinding, measurement validity, and standardized assessment". The net effect was that it was impossible to compare various trials or to come to any conclusions about best practice. 


\section{What outcomes should be evaluated?}

\section{1 outcomes categories:}

There are few publications that attempt to evaluate transition programs for epilepsy. Outcomes that might be considered fall into four categories. First, it is important to assess what happens to the seizures. This could involve counting seizures directly, using other clinical outcomes (episodes of status epilepticus, death from SUDEP), or health services outcomes such as attendance at follow clinics, hospitalizations, emergency room visits, or treatment adherence. Secondly, mental health and psychosocial issues are important and include assessments for both mood disorders and suicide attempts as well as more general measures of psychosocial function such as marriage or divorce. Third, there are issues of finances and legal supports such as employment for those with normal intelligence or guardianship for those with intellectual disability. The cost of care is also relevant. Fourth, assessments of patient/parent satisfaction and quality of life are important.

We are not aware of any study that has assessed such a broad array of outcomes in epilepsy around the time of transition/transfer. Several epilepsy cohort studies have assessed transition/transfer experiences for youth with epilepsy, although each study has used restricted outcome measures.

\subsection{Programs that assessed transition and transfer experiences:}

\subsubsection{Colorado children's hospital, Aurora, Colorado, USA:}

One such study from Colorado studied youth with refractory epilepsy who were of an age when transfer to adult care would be appropriate..$^{11}$ The authors developed several interventions and chose the time from referral to the time of visit with the adult service as the primary outcome measure. Also assessed was the effect of an education program on self-management. As well, they counted referrals to social work, whether there was any change in self-care, and considered the satisfaction level of the pediatric epilepsy service providers. Over time, there was a decrease in the time of referral to being seen in adult services and an increase in the counted referrals to social work. However, there were no significant changes in the outcome measures. The study had no data about seizure control or other changes once the transfer had been completed.

\subsubsection{Necker Enfants Malades hospital, Paris, France:}

A study from Paris of 31 patients with Dravet syndrome who had already been transferred to adult care used a series of Likert-type scale questions completed by parents to assess their experiences of transition. ${ }^{12}$ Questions were divided into three groups: the pediatric experience, the time of transfer, and the first two years in adult care. Nearly all patients reported a great deal of satisfaction with both their pediatric and adult neurology care, although "92\% of the families felt that the adult neurologist did not give them enough autonomy to make decisions." Sixty percent of families reported that their preparation for transfer was satisfactory, but $40 \%$ reported their preparation as 'inadequate". Five factors strongly predicted satisfaction with transfer preparation: quality of transition preparation, longer duration of follow up in pediatrics with the same 
child neurologist, good availability of pediatric staff, age $>18$ years at the time of transfer and "good health condition" at the time of transfer.

\subsubsection{Children's hospital, Edmonton, Alberta, Canada:}

A nurse-led transition clinic in Edmonton is described in the accompanying paper. ${ }^{5,13} \mathrm{~A}$ series of Likert-type questions was completed by 144 patients (or parents if the child had intellectual disability) two months after the first adult epilepsy clinic assessment. Nearly all respondents indicated that the nurse-led transition program was appropriate, decreased their fears, and made them aware of the differences to expect between pediatric and adult care. This transition program involved both the pediatric and adult epilepsy nurse practitioners and all respondents indicated that it was particularly helpful to have met the adult nurse prior to their first adult epilepsy clinic visit.

Therefore, it is clear that comprehensive, empirical evidence is scarce for the outcomes of transition programs for youth with any chronic disease and nearly non-existent for epilepsy. A theoretical framework could assist further research. One example of such a framework is the Triple Aim Framework which considers three major categories of outcome. ${ }^{14}$ First are outcomes related to population health, such as adherence to guidelines, disease specific outcomes like seizure control or mortality, and patient reported outcomes such as quality of life and self-care skills. Second is patient care experiences, such as satisfaction with care, and identification of facilitators and barriers to accessing care. Third are outcomes related to cost, which include gaps in care, costs of "no shows" for follow up care, costs per patient, service use (both short-term and long term) and location of care (i.e., outpatient vs. emergency vs. inpatient care). Although few studies have considered all three groups of outcomes, the Triple Aim framework is of great value because it aligns transition interventions with system-wide improvements in health care.

Few studies of transition have used the Triple Aim Framework. A meta-analysis considered studies that described an intervention for transition for pediatric to adult care including patients with and without a chronic condition. ${ }^{14}$ Included were studies that compared experiences pre and post intervention or compared an intervention with a comparison group. Thirty-three studies met the inclusion criteria. Twenty-seven studies used "population health" measures, mainly disease-specific. Fifteen studies assessed the cost, mainly service utilization. Eight studies addressed "experience of care", mainly satisfaction. There were only three studies that examined all three overall domains of the Triple Aim Framework and these were all studies of Type 1 Diabetes. ${ }^{15-17}$ These studies suggested that in the short run the control of diabetes was not altered to a significant degree but attendance at follow up was considerably better with transition programs. 


\section{Treatment Needs of the Epilepsies}

There are no ideal "rules" about when to transfer a young person with epilepsy to adult care. In some jurisdictions, it is simply the age of patient that is considered. However, it is worthwhile to consider some of the issues that are better dealt with in pediatrics and others that might be better managed in the adult setting. These considerations will impact the cost of transition

\subsection{Self-limited epilepsies}

These are mainly patients with Rolandic epilepsy. Seizures have resolved by mid adolescence but there may be some residual learning issues; however, the long term social outcome is typically normal. ${ }^{18} \mathrm{~A}$ family physician or general internist in a community setting would seem more than adequate for ongoing care. Transition for these patients could be the same as for any healthy adolescent and there would be no extra costs.

\subsection{Idiopathic Generalized Epilepsies that persist}

Juvenile myoclonic epilepsy (JME) is most important in this category. Here the diagnosis should be well established during adolescence and the patient needs to prepare for a lifetime of AED treatment even though some patients with JME will eventually have complete remission and no longer require medication. ${ }^{19,20}$ Seizures are typically well controlled with medication. Of importance, the epidemiology of JME suggests most but a majority of these patients are female, and thus issues of contraception and pregnancy are very important. These latter concerns are often more familiar to adult neurologists/epileptologists and earlier transfer during adolescence may be appropriate rather than waiting for young adulthood. Transition teaching during the pediatric years should likely focus on compliance and introduce issues of sexuality, restrictions, life style and eventual employment, which need to be continued in adult care. These themes span both pediatric and adult care and will likely be associated with some incremental costs such as social work or employment counselling.

\subsection{Epileptic and developmental encephalopathies}

Here the child neurologist/epileptologist is likely best informed about the nature of the epilepsy, its causes, co-morbidities, natural history and treatment. Adult epileptologists may be unfamiliar with the epilepsy syndromes, etiologies, and complex treatments with special AEDs or diets. The management of intellectual disability (ID) and difficult behavior problems may be very challenging in late adolescence. It is ironic that many of these children end up as adults in institutional care where their very complex epilepsy may be managed by family physicians or psychiatrists with or without occasional consultations with adult epileptologists. Transition/transfer costs may be substantial because of the important role for social workers, nurses, psychologists and institutional care givers. An ideal arrangement might be co-care with both pediatric and adult epileptologists. 


\subsection{Drug resistant focal epilepsy}

Until recent times, adult epilepsy care has been more focused on epilepsy surgery compared with pediatric care ${ }^{21}$. Arguably, earlier transfer to adult care for youth with drug resistant focal epilepsy is appropriate to identify those with surgical options especially if the pediatric team does not have this expertise. The cost of transition/transfer may then include a major epilepsy surgery workup which is expensive but potentially cost effective if seizures are "cured" earlier in life by surgery leading to the possibility of more years of productive employment.

Clearly the timing of transfer to adult care and choice of adult epilepsy provider is best seen as an individualized decision, based on the type of the epilepsy and on the local facilities and care programs.

\section{Costs \& Financing of Transition Programs}

Creating a successful transition program requires financing to develop, implement, and sustain the operations of the program. The source and justification for funding will depend strongly on the national health care policy environment. In some countries, healthcare is supported extensively by the state. All the necessary resources represent costs and must be offset with improved clinical outcomes (i.e. fewer seizures, improved quality of life), reduced downstream uses of health care resources such as emergency rooms, or improved social and employment outcomes. Alternatively, in a fee-for-service environment, such as occurs in much of the United States healthcare system, some of these resources can be reframed as revenue, or as a means to improve patient satisfaction and reputation of the institution.

When deciding to implement a transition program, a medical center will need to balance the scope of a program with the degree of funding available. A minimal program might focus only on drafting a transfer note. Greater costs will be incurred by increasingly comprehensive transition programs, which might include a re-evaluation of etiology or a dual clinic with the pediatric and adult team. A nephrology program in Vancouver was able to demonstrate the cost effectiveness of a kidney transplant transition program, facilitated by the use of a clearly defined clinical outcome- loss of the transplanted kidney. ${ }^{22}$ Prior to the transition program, a simple transfer system was used to pass youth along to adult nephrology care. There was a high rate of kidney rejection presumably related to poor compliance with the net effect that several youth had to return to dialysis, a costly treatment. Following the introduction of an extensive transition program, loss of the transplanted kidney dropped to zero. The cost of the transition program was much less than the previous costs for dialysis, hence the program was deemed highly cost effective. To the best of our knowledge this is the only transition plan that has been assessed for cost effectiveness. Such straight forward outcome measures are difficult to establish in epilepsy transition programs.

A Delphi approach included 93 participants (including physicians, health care experts and parents of children with chronic illness) to recommend the most desirable 
outcomes for transition. ${ }^{23}$ At the end of three cycles, it was concluded that the following in descending order were the most important outcomes: achieving optimal quality of life, patient self-managing the patient's own condition, understanding characteristics of conditions and complications, knowing the names and purpose of medications, adhering to medications and/or other treatment, attending most medical appointments, having a medical (health) home, avoiding unnecessary hospitalizations, understanding health insurance options, having a social network of friends. Many of these outcomes would be difficult to assess in a cost effectiveness analysis.

\subsection{Estimation of costs for transition programs}

In an attempt to estimate the costs of a transition program in epilepsy, we considered the seven recommendations of the Ontario task force on transition for people with epilepsy - introduce the concept of transition, explore available financial, community and legal supports, determine transition readiness, screen for risk factors for poor transition, re-think diagnosis and re-investigate if appropriate, identify obstacles for patients with drug resistant epilepsy, and prepare pediatric discharge package. ${ }^{24}$ To accommodate these recommendations within a new transition program there would be startup costs. Each of the seven recommendations has an associated cost including personnel (physician, nursing, social work and other professionals), modifications to the electronic medical record, and clinic space. Possibly the most expensive would be reinvestigating the etiology of the epilepsy that might be justified in perhaps a third of patients. These investigations could involve admission to an epilepsy monitoring unit, an MRI with sedation and extensive genetic testing. In a fee-for-service health care system, the revenue from the re-investigation may outweigh the other transition clinic expenses making the transition program "cost effective". In a single payer government run system it will be more complicated to establish cost effectiveness because it will be necessary to evaluate costs after the transition process has been completed using factors such as number of emergency room visits and impact on family income and generation of income taxes.

\subsection{Estimation of financial benefits from transition programs:}

There are some published data to help estimate the financial benefits of transitions programs. For programs that promise reductions in unnecessary hospital use, a public accountable care organization in the United States found that for a child with epilepsy, a typical emergency department visit costs USD \$640, and an unscheduled inpatient admission USD $\$ 18,066 .{ }^{25}$ Of importance, the distribution of inpatient costs have a long tail - an admission for child with refractory status epilepticus regularly costs USD $\$ 150,000$ - $\$ 300,000$, and in extreme cases costs may exceed USD $\$ 1$ million. ${ }^{26}$ For programs that promise improvements in seizure control, several reports show that the cost of care for individuals with uncontrolled epilepsy is significantly higher than for controlled epilepsy. A recent review found that in the US, epilepsy-attributable direct costs ranged from $\$ 1022-\$ 9327$ per patient per year for individuals with controlled epilepsy, compared to $\$ 8592-\$ 19,749$ for individuals with uncontrolled epilepsy. ${ }^{27}$ 
Similar estimates for other countries, both in the developed and developing world, have been recently reviewed. ${ }^{28}$ For programs that promise an increase in epilepsy surgery, economic analyses have shown improvements in survival and quality-adjusted life expectancy ${ }^{29}$ and overall reduced costs over $9-10$ years. ${ }^{30}$ And finally, some programs may promise reductions in indirect costs, e.g. the costs from unemployment, underemployment, and missed work for people with epilepsy and their caregivers. ${ }^{31} \mathrm{~A}$ Spanish study estimated that indirect costs were higher than the direct costs, $€ 1055$ euros direct vs $€ 1528$ indirect over 6 months in their cohort of 171 adults with epilepsy. ${ }^{27}$

\section{Conclusions}

We conclude that transition programs in general have not been well evaluated, and that evaluation data about epilepsy programs is particularly lacking. In the absence of such data showing the benefits of these program and enabling the cost effectiveness evaluation, epilepsy transition programs may be expensive and difficult to implement. We urge that more efforts be made to prove the value of these programs.

Acknowledgements: We thank Mrs Carolin Wenzel who helped for the logistic organisation of the symposium

Funding sources: This symposium was supported by unrestricted educational grants from UCB Biopharma SPRL, Eisai Europe Ltd and GW Research Ltd. The funding sponsors had no input into the program and have not seen this manuscript prior to its publication. 
References

[1] Transition of epilepsy care from children to adults. Epilepsia. 2014;55 Suppl 3:153.

[2] Nabbout R, Andrade DM, Bahi-Buisson N, Cross H, Desquerre I, Dulac O, et al. Outcome of childhood-onset epilepsy from adolescence to adulthood: Transition issues. Epilepsy Behav. 2017;69:161-169.

[3] Nabbout R, Camfield CS, Andrade DM, Arzimanoglou A, Chiron C, Cramer JA, et al. Treatment issues for children with epilepsy transitioning to adult care. Epilepsy Behav. 2017;69:153-160.

[4] Camfield P, Camfield C, Busiah K, Cohen D, Pack A, Nabbout R. The transition from pediatric to adult care for youth with epilepsy: Basic biological,sociological, and psychological issues. Epilepsy Behav. 2017;69:170-176.

[5] Camfield PR, Andrade D, Camfield CS, Carrizosa-Moog J, Appleton R, Baulac M, Brown L, Ben Menachem E, Cross H, Desguerre I, Grant C, Hosny H, Jurasek L, Mula M, Pfäfflin M, Rheims S, Ring H, Shellhaas RA, Viyanan KP, Wirrell $E$ and Nabbout R. How can transition to adult care be best orchestrated for adolescents with epilepsy? Epilepsy Behav

[6] Suris JC, Akre C. Key elements for, and indicators of, a successful transition: an international Delphi study. J Adolesc Health. 2015;56:612-8.

[7] National Institute for Health and Care Excellence (NICE). Transition from children's to adults' services for young people using health or social care services, Guideline 43. London: National Institute for Health and Care Excellence (NICE); 2016. https://www.nice.org.uk/guidance/ng43/evidence/full-guideline-pdf2360240173 (accessed August 18, 2018)

[8] Colver A, McConachie H, Le Couteur A, Dovey-Pearce G, Mann KD, McDonagh JE,Pearce MS, Vale L, Merrick H, Parr JR; Transition Collaborative Group. A longitudinal, observational study of the features of transitional healthcare associated with better outcomes for young people with long-term conditions. BMC Med. 2018;16:111.

[9] Campbell F, Biggs K, Aldiss SK, O'Neill PM, Clowes M, McDonagh J, While A, Gibson F. Transition of care for adolescents from paediatric services to adult health services. Cochrane Database Syst Rev. 2016 Apr 29;4:CD009794.

[10] Le Roux E, Mellerio H, Guilmin-Crépon S, Gottot S, Jacquin P, Boulkedid $\mathrm{R}$, Alberti $\mathrm{C}$. Methodology used in comparative studies assessing programs of transition from paediatrics to adult care programs: a systematic review. BMJ Open. 2017;7:e012338. 
[11] Disabato JA, Cook PF, Hutton L, Dinkel T, Levisohn PM. Transition from Pediatric to Adult Specialty Care for Adolescents and Young Adults with Refractory Epilepsy: A Quality Improvement Approach. J Pediatr Nurs. 2015;30:e37-45.

[12] Kuchenbuch M, Chemaly N, Chiron C, Dulac O, Nabbout R. Transition and transfer from pediatric to adult health care in epilepsy: a families' survey on Dravet syndrome. Epilepsy Behav. 2013;29:161-5.

[13] Jurasek L, Ray L, Quigley D. Development and implementation of an adolescent epilepsy transition clinic. J Neurosci Nurs. 2010;42:181-9.

[14] Prior M, McManus M, White P, Davidson L. Measuring the "triple aim" in transition care: a systematic review. Pediatrics. 2014;134:e1648-61

[15] Cadario F, Prodam F, Bellone S, et al. Transition process of patients with type 1 diabetes (T1DM) from paediatric to the adult health care service: a hospital based approach. Clin Endocrinol . 2009;71:346-350

[16] Kipps S, Bahu T, Ong K, et al. Current methods of transfer of young people with type 1 diabetes to adult services. Diabetic Med. 2002;19:649-654

[17] Van Walleghem N, Macdonald CA, Dean HJ. Evaluation of a systems navigator model for transition from pediatric to adult care for young adults with type 1 diabetes. Diabetes Care. 2008;31;1529-1530

[18] Camfield CS, Camfield PR. Rolandic epilepsy has little effect on adult life 30 years later: a population-based study. Neurology. 2014;82:1162-6.

[19] Camfield CS, Camfield PR. Juvenile myoclonic epilepsy 25 years after seizure onset: a population-based study. Neurology. 2009;73:1041-5.

[20] Baykan B, Martínez-Juárez IE, Altindag EA, Camfield CS, Camfield PR. Lifetime prognosis of juvenile myoclonic epilepsy. Epilepsy Behav. 2013;28 Suppl 1:S18-24

[21] Ryvlin P, Cross JH, Rheims S. Epilepsy surgery in children and adults. Lancet Neurol. 2014;13:1114-1126.

[22] Prestidge C, Romann A, Djurdjev O, Matsuda-Abedini M. Utility and cost of a renal transplant transition clinic. Pediatr Nephrol. 2012;27:295-302

[23] Fair C, Cuttance J, Sharma N, Maslow G, Wiener L, Betz C, Porter J, McLaughlin S, Gilleland-Marchak J, Renwick A, Naranjo D, Jan S, Javalkar K, Ferris M;International and Interdisciplinary Health Care Transition Research Consortium. International and Interdisciplinary Identification of Health Care Transition Outcomes. JAMA Pediatr. 2016;170:205-11. 
[24] Andrade DM, Bassett AS, Bercovici E et al. Epilepsy: Transition from pediatric to adult care. Recommendations of the Ontario epilepsy implementation task force. Epilepsia. 2017;58:1502-1517.

[25] Patel AD, Terry D, Moore JP, et al. Reduction of emergency department visits using an urgent clinic for children with established epilepsy. Neurology Clinical practice 2016;6:480-6.

[26] Keros S, Buraniqi E, Alex B, et al. Increasing Ketamine Use for Refractory Status Epilepticus in US Pediatric Hospitals. Journal of Child Neurology 2017;32:638-46.

[27] Begley CE, Durgin TL. The direct cost of epilepsy in the United States: A systematic review of estimates. Epilepsia 2015;56:1376-87.

[28] Allers K, Essue BM, Hackett ML, et al. The economic impact of epilepsy: a systematic review. BMC Neurology 2015;15:245.

[29] Choi H, Sell RL, Lenert L, et al. Epilepsy surgery for pharmacoresistant temporal lobe epilepsy: a decision analysis. JAMA 2008;300:2497-505.

[30] Picot MC, Jaussent A, Neveu D, et al. Cost-effectiveness analysis of epilepsy surgery in a controlled cohort of adult patients with intractable partial epilepsy: A 5-year follow-up study. Epilepsia 2016;57:1669-79.

[31] Pato Pato A, Cebrian Perez E, Cimas Hernando I, Lorenzo Gonzalez JR, Rodriguez Constenla I, Gude Sampedro F. Analysis of direct, indirect, and intangible costs of epilepsy. Neurologia 2011;26:32-8. 
Table 1

Suggested key elements for transition programs

\begin{tabular}{|l|l|l|l|l|}
\hline & $\begin{array}{l}\text { NICE } \\
\text { Guidelines }\end{array}$ & $\begin{array}{l}\text { Delphi } \\
2015\end{array}$ & $\begin{array}{l}\text { Delphi } \\
2016\end{array}$ & $\begin{array}{l}\text { Ontario } \\
\text { Guidelines }\end{array}$ \\
\hline Age banded clinic & $\mathrm{x}$ & & & \\
\hline Meeting with adult team before transfer & $\mathrm{x}$ & & & \\
\hline Promotion of health self efficacy & $\mathrm{x}$ & $\mathrm{x}$ & $\mathrm{x}$ & \\
\hline $\begin{array}{l}\text { Written transition program including } \\
\text { transfer summary }\end{array}$ & $\mathrm{x}$ & $\mathrm{x}$ & & $\mathrm{x}$ \\
\hline Appropriate parental involvement & $\mathrm{x}$ & $\mathrm{x}$ & & \\
\hline Key transition worker & $\mathrm{x}$ & $\mathrm{x}$ & & \\
\hline Co-ordinated heath care team & $\mathrm{x}$ & & & \\
\hline Holistic life skills training & $\mathrm{x}$ & & $\mathrm{x}$ & \\
\hline Transition manager & $\mathrm{x}$ & $\mathrm{x}$ & & \\
\hline Start transition program at early age & & $\mathrm{x}$ & & \\
\hline Seeing patient alone & & $\mathrm{x}$ & & \\
\hline Identifying adult provider & & $\mathrm{x}$ & & \\
\hline $\begin{array}{l}\text { Ensuring that first appointment takes } \\
\text { place }\end{array}$ & & $\mathrm{x}$ & & \\
\hline Informing primary health care providers & & $\mathrm{x}$ & & \\
\hline Assessing risk behaviors & & $\mathrm{x}$ & & $\mathrm{x}$ \\
\hline $\begin{array}{l}\text { Understanding characteristics of } \\
\text { conditions and complications }\end{array}$ & & & $\mathrm{x}$ & \\
\hline $\begin{array}{l}\text { Adhering to medications and/or other } \\
\text { treatment, }\end{array}$ & & $\mathrm{x}$ & $\mathrm{x}$ & \\
\hline Attending most medical appointments & & $\mathrm{x}$ & $\mathrm{x}$ \\
\hline Having a medical (health) home & & & $\mathrm{x}$ & \\
\hline Avoiding unnecessary hospitalizations \\
\hline $\begin{array}{l}\text { Understanding health insurance options } \\
\text { and community supports }\end{array}$ & & & & \\
\hline Having a social network of friends. & & & & \\
\hline Re-think diagnosis and re-investigate if & & & & \\
\hline
\end{tabular}




\begin{tabular}{|l|l|l|l|l|}
\hline appropriate, prior to transfer & & & \\
\hline $\begin{array}{l}\text { Identify obstacles for patients with drug } \\
\text { resistant epilepsy, }\end{array}$ & & & & $\mathrm{x}$ \\
\hline
\end{tabular}

